\title{
Inclusion and Identification of Locally- Authored Items in Library Collections
}

\section{Rynnelle Wiebe ${ }^{1}$}

${ }^{1}$ School of Library and Information Studies, University of Alberta, Email:rynnelle@ualberta.ca

To Cite:

Wiebe, R. (2021). Inclusion and identification of locally-authored items in library collections. Pathfinder: A Canadian Journal for Information Science Students and Early Career Professionals, 2(1), 18-34. https://doi.org/10.29173/pathfinder37

\begin{abstract}
This research explores how public libraries support local authors, with a focus on if and how these works are included in library collections and made findable to patrons. Twelve public libraries, four each from British Columbia, Alberta, and Saskatchewan, were selected to analyze collection development policies and item metadata. Qualitative content analysis was used to code collection policies, and systemic analysis of item record metadata was used to understand methods of identifying locally-authored items. The results of this research indicate that collection policies provide both opportunities and barriers for acquisition of locally-authored items, including those items that are self-published. There is a lack of consistent methods for identifying items as locally-authored within item metadata. This research discusses some of the challenges associated with identifying items as locally-authored, and concludes with recommendations for modifying collection policies and methods for identifying items in order to make locally-authored items more accessible and discoverable to the local community.
\end{abstract}

Keywords: local authors, public libraries, self-publishing, collection policies, cataloguing, metadata

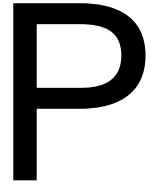

ublic libraries serve their communities and hold collections that reflect the information interests and needs of library users. Collections that contain works by local authors provide patrons with materials relevant to local issues and perspectives and can contribute to a sense of community identity. Including these items in library collections provides opportunities for local authors to share their work with the community, while gaining exposure and growth as an author (DeWild \& Jarema, 2015). Locally-authored items may be written by new authors, self-published, or published by independent companies rather than conventionally. As a result, collection policy 
selection criteria may pose challenges for including these items in library collections. When locally-authored items are included, it is important that these items are findable by community members in order to support the authors and provide relevant materials to library users.

To explore how public libraries support local authors, this research addressed the following questions:

- How do urban public libraries support local authors, including those who choose to self-publish?

- How do collection policies present opportunities or barriers for including works by local authors and/or self-published items?

- How is metadata used to identify items by local authors?

Using a pragmatic paradigm, these research questions inform the mixed methods selected for analysis as discussed in the Methods Section. Collection policies, which inform how items are selected for the library's collection, and locally-authored item metadata are sources of data for this research.

\section{Literature Review}

Literature addressing the relationship between public libraries and local authors is scarce; however, many scholars reference local authors within their discussions of self-publishing. Dilevko and Dali (2006) explain that because large publishing companies select manuscripts that will be "guaranteed bestsellers" that produce a profit, it is difficult for new authors and even those who have published a small number of books to be published by these conventional publishing companies (p. 209). As a result, local authors often choose to self-publish, and are considered in the literature alongside discourse about self-publishing as is discussed here.

\section{Value of Locally-Authored Materials}

Including locally-authored items in library collections provides patrons with materials relevant to their community, its residents, and history (Bijali \& Khan, 2018). Dawson (2008) argues that collecting items of local interest and by local authors, including self-published items, is valuable for the library community. Mullock (2019) further explains that locally-authored self-published items meet the information and entertainment needs of the community, and memoirs in particular "reflect the soul of the 
community" (p. 473). These descriptions of the value of local items fits with the American Library Association's (ALA, 2016) interpretation of the Library Bill of Rights' Diverse Collections, which states that "[I]library workers have an obligation to select, maintain, and support access to content on subjects by diverse authors and creators that meets-as closely as possible - the needs, interests, and abilities of all the people the library serves" (para. 2). Materials written by members of the community are likely to achieve this and be relevant to the interests and perspectives of community members and their shared sense of identity; Bradley et al. (2012) describe these items of community interest as "deal[ing] with local history and local people because the writers [a]re local" (p. 132). DeWild and Jarema (2015) found that identifying library items as "local" increased interest in the items, and that featuring self-published local authors in collections and programming supported local authors by providing venues for growth and increased sales. Additionally, collecting locally-authored materials "facilitate[es] the exchange of ideas among users," which the ALA interprets as contributing to information literacy stated in the Library Bill of Rights (ALA, 2009, para. 5). Collecting locally-authored items provides relevant materials to meet the needs and interests of the community.

\section{Challenges of Collecting Locally-Authored Items}

While collecting locally-authored materials is valuable, the literature discusses challenges for libraries when acquiring these items. For example, England (1948) found that of 175 libraries with a local author collection, the methods of establishing this collection varied, with one main challenge being defining what is meant by "local author." Definitions of "local" vary from residence or place of education of the creator, to the topic they write about, and "local author collections" may be synonymous with "local history collections" (p. 340). This has practical implications in determining how items are selected for library collections, and also influenced how data was selected for this research as discussed in the Methods Section.

Additionally, it can be difficult for libraries to identify self-published items suitable for inclusion in library collections. As DeWild and Jarema (2015) state, libraries rely on the processes of traditional publishing, including teams of editors, designers, and marketers that ensure the items are cohesive and well-designed. Self-published items 
are often associated with lower quality writing or content (DeWild \& Jarema, 2015; Dilevko \& Dali, 2006; Mullock, 2019), and Sandy (2016) states that it is the processes of editing, design, and marketing that produce "high-quality books" (p. 894). Without these processes, libraries may be hesitant to acquire self-published items. Additionally, DeWild and Jarema (2015) reference the efficiency of acquiring items through vendors, viewing items with their publishing information, and reading professional reviews. Selfpublished items, however, are not always included in professional review journals (Culley, 2017; Dilevko \& Dali, 2006). Without reviews or publication information, the topic and audience of a self-published item may be unclear, requiring library staff to read the book themselves or do additional research to determine if the item meets selection criteria (DeWild \& Jarema, 2015). These additional steps may prevent libraries from seeking locally-authored or self-published materials for acquisition.

Once selected for acquisition, self-published items often require original cataloguing. Bibliographic records are rarely available for self-published items through the Library of Congress Cataloging in Publication program or its own collection (Holley, 2015). Similarly, these items do not often come through a vendor and may lack complete publishing information (DeWild \& Jarema, 2015). Consequently, library staff must do original cataloguing, relying on additional staff time and resources (DeWild \& Jarema, 2015; Tuncer \& David, 2019), and resulting in a lack of bibliographic control for self-published items (Bradley et al., 2012; Holley, 2015). In their study of self-published item records, Tuncer and David (2019) found a lack of standards for publisher, place of publication, and date of publication metadata (MARC 260 and 264). To address this, they recommended the development of best practices to support these items' visibility and access. The need for original cataloguing and the lack of bibliographic control reduces library users' ability to find and access these materials, negatively affecting the authors of these items.

There are some recommendations within the literature to address these challenges. For example, Pacer (2013) argues that libraries should utilize media other than traditional review journals and vendor sites to determine items for collections, and Dawson (2008) suggests that librarians communicate directly with self-publishing authors and browse self-publishing company catalogues. Instead of requiring objective, 
unpaid reviews through review journals, Mullock (2019) recommends that the library set up a volunteer review board to provide reviews for local authors. Additionally, to improve the development of item metadata, DeWild and Jarema (2015) discuss Kent Library's Indie Collection that requires local authors to submit a form with the item's details, and Bradley et al. (2012) argue that the involvement of libraries in self-publishing will improve bibliographic control of these items. These recommendations will be further addressed in the Discussion of this paper.

While these articles discuss the inclusion of locally-authored materials in libraries, the emphasis remains on self-published materials, leaving a gap in the literature around local authors. In order to begin to address the unique relationship and challenges facing public libraries and local authors, this paper focuses on locallyauthored item acquisition and cataloguing through analysis of collection policies and item metadata.

\section{Methods}

This research was conducted in two parts, exploring both collection policies and item metadata. The first part uses qualitative content analysis to identify common themes in collection policies, providing insight into how librarians make decisions around selection and evaluation of collection materials (Kelly, 2015). This provides insight into how selection criteria creates opportunities or barriers for including locallyauthored items. Qualitative content analysis was chosen for this research because it allows concepts and patterns to emerge directly from the text (White \& Marsh, 2006). The second part uses systematic analysis of item metadata, including the content of selected MARC fields and online catalogue data. The purpose of this analysis was to identify common methods for identifying items as locally-authored. Collection policies and item metadata are selected sources of information to allow for emerging themes and frequent methods to be compared and corroborated (Bowen, 2009) among libraries.

The sample of policies and metadata for this research was limited to twelve public libraries in urban centres, four each from British Columbia (BC), Alberta ( $A B)$, and Saskatchewan (SK). Three provinces were selected for this research due to the limited timeline and scope of the project. Libraries were selected first by generating a list of 
cities from each province using Statistics Canada (2019) 2016 Census data, and then four cities from each province were selected using a random item selector. The website for each city's public library was searched for the collection policy, which was downloaded for analysis. When collection policies were unavailable, the library was contacted. Cities are anonymized in this report (BC1-4, AB1-4, SK1-4), and when cities are named in the data, "Location" is used in this analysis.

The sample of metadata was selected based on identifying authors from each city, using a Google search, resulting in 54 authors from the 12 cities. As was identified in the Literature Review section, there is no standard definition of "local" author, and so guidelines were developed for this research. The included authors either currently live in the city, or were born, lived, or worked in the city in the past. When local authors from a city could not be identified, authors from nearby communities were included based on the criteria that they were identified as "local" in news articles or author biographies. The selected authors were searched for in the corresponding library's online catalogue, and a maximum of three items per author were selected for the sample, resulting in 78 items.

When analyzing collection policies, open coding was used to identify content and themes. This is an inductive approach, in which coding is guided by research questions and the data itself (White \& Marsh, 2006); however, themes identified through the literature review also influenced how the policies and metadata were understood. The text was read, and units of information were given initial codes based on the meaning of the unit of information. The initial codes and corresponding content were reviewed to filter and focus the content into themes (Saldaña, 2009). Definitions for the themes were developed from the coded content, and the coding was reviewed again. A similar process was used for metadata analysis: metadata was coded by method of identifying local authorship and content of this identification, and the codes were grouped into general methods. Adhering to the procedures of document analysis, only relevant sections of policies and metadata were coded, as policy documents and item metadata are developed to serve various purposes (Gross, 2018). The identified collection policy themes and metadata methods are identified in the Results section. 
WIEBE

\section{Results}

\section{Collection Policy Themes}

The following themes were identified from the coded policies: communityoriented collections, diversity, local interest, quality, reviews, and reputation of the creator. Other themes coded from the policies such as intellectual freedom and practical considerations of size and cost are out of scope for this research. This section identifies and describes each theme, which will be discussed in consideration of locally-authored items in the Discussion section.

\section{Community-Oriented Collections}

All twelve collection policies discussed the purposes of library collections as meeting the needs and interests of the community. These needs are discussed broadly as relating to information, recreation, education, culture, artistic, or leisure. To describe the community, some policies refer to a general group of people, such as AB2's "the public," AB4's "large group of people with varied backgrounds," or AB1's "average citizen." Policies may also specify demographics within the community, such as AB1's "pre-school and adult" groups or BC2's acknowledgement of "individuals with diverse [...] needs". Overall, this theme is present throughout the policies, and establishes the purpose of library collections as serving the community.

\section{Collection Diversity}

Collection Diversity is about making diverse materials from a variety of perspectives and subjects available to library users. This theme was discussed in each of the twelve library policies. This connects closely with Community-Oriented Collections in that it is often referenced as serving diverse community needs ( $A B 3, A B 4$, $\mathrm{BC} 2, \mathrm{SK} 2, \mathrm{SK} 3, \mathrm{SK} 4)$. The policies describe collections as including various views and subjects (AB2, BC3, SK2, SK3, SK4), others describe their collections as being "balanced" (AB3, BC4) and presenting "all sides of an issue" (BC4), including specifically representing "minority points of view" (BC3).

To support collection diversity, nine policies identify the importance of selecting items that supplement existing collections (AB1, AB3, AB4, BC2, BC3, BC4, SK1, SK2, SK4). This involves recognizing existing materials on the subject within the collection, 
and where the collection could use support. Specifically, five of these policies look to add materials when the current collection lacks related materials and to avoid duplication (AB1, AB4, SK1, SK2, SK4), thus adding to the diversity of the collection. $A B 1$ also considers the "availability of material elsewhere in the area," and, four policies ( $A B 1, A B 3, S K 2, S K 4)$ limit the materials within the library collection to those not already made available through other libraries, such as school, academic, or special libraries.

\section{Local Interest}

Only six library policies discussed acquiring items of local interest, local history, or local significance. The geographic areas vary from "local" (AB3, BC2, SK2, SK4) to naming the region (AB3), province (SK2, SK4), or Canadian authors and content (BC3, $\mathrm{BC} 4, \mathrm{SK} 2, \mathrm{SK} 4)$. It is important to note that some policies include language such as AB3's "about and of" the local region, and BC4's "local significance of the author or creator," which demonstrates that local interest does not depend on the subject of the item, but also includes the creator.

\section{Quality of Materials}

Eight policies identify quality within their selection criteria (AB1, AB4, AB3, BC3, BC4, SK1, SK2, SK4). This differs between policies as some emphasize the physical condition (AB1, AB4, SK1) while others refer to the "format," though it is unclear if this is the style of the content or the physical format (SK2, SK4). Content and writing are also considered in terms of quality and suitability (AB3, AB4, BC3, BC4, SK2, SK4), as well as generally comparing the item to others (AB1).

Similarly, seven policies refer to the value or importance of a work. The "importance" of the subject is described by AB1, AB4, SK2, SK4, and current and future value of an item is identified by AB1, AB3, and BC4. Additionally, SK3 also refers to the "literary and artistic merit" and "authenticity and honesty of presentation" within a work.

\section{Reviews}

Nine policies discuss selection based on positive reviews. The type of review varies among library policies, including professional book reviewers or critics (AB1, $A B 4, B C 2, B C 3, B C 4, S K 2, S K 4)$, such as those in review journals, or bibliographies and indexes (AB1). Some policies state that selection can be based on professional opinion or judgement, including that of a librarian (AB1, AB2, AB3, SK2, SK4). 
Additionally, some list the public or popular opinion as influencing item selection (AB4, $\mathrm{BC} 3, \mathrm{SK} 2, \mathrm{SK} 4)$, and AB4 includes awards as an indication of this.

\section{Reputation of the Creator}

This theme focuses on the "significance" or "authority" of the creator, including the author, illustrator, or publisher. Six collection policies include the creator's reputation within item selection criteria (AB1, AB4, BC3, BC4, SK2, SK4).

\section{Metadata Analysis}

Of the 78 items in the sample, 38 included metadata that identified the item as locally-authored (48.7\%). In this case, "local" identification includes a description or reference to either the genre or author as being from the local city, region, or province (Canadian is not included as "local" for this research). Three methods were analyzed as identifying local authors: MARC Subject Headings, Genre/Form, and Local Subject Headings; Lists and Collections; and Notes.

\section{Subject Headings, Genre/Form, and Local Subject Headings (MARC 650, MARC 655, MARC 690)}

Subject Headings, Genre/Form, and Local Subject Headings are grouped as a single method of identifying items as locally-authored as not all libraries differentiate between them or provide MARC records on their online catalogues. Using these fields, libraries identify local authors through two methods: identifying the author (e.g. Alberta author) or identifying the genre of work (e.g. Saskatchewan fiction). It is important to note the difference between the genre of the work and the subject, items with a local subject (e.g. British Columbia-Fiction) do not necessarily identify the item as created by a local author. Items with a local place identified in the genre do identify the item as created locally. As stated above, metadata referring to the city, region, or province is considered local in this analysis.

Nineteen of 78 items were identified as locally-authored through MARC fields $650,655,690$. Table 1 displays the method used for identifying local authorship (Author or Genre location), and the specificity of location identified (city, region, province). 
Table 1

Methods of Identifying Local Items in MARC Records

\begin{tabular}{lccc}
\hline \multicolumn{1}{c}{ Method } & Region/Province & City + Region/Province & Total \\
\hline Author's location & 11 & 5 & 16 \\
\hline Genre (e.g., Saskatchewan & 1 & 0 & 1 \\
fiction) & & & 2 \\
\hline Author's location + Genre & 1 & 1 & 19 \\
\hline Total & 13 & 6 &
\end{tabular}

\section{Lists and Collections}

Libraries may utilize lists and collections to group similar items. Some libraries curate online lists based around themes, authors, award winners, genres, or local items; these are not indicated in the MARC record but are identified through links to the list in the online catalogue. Physical collections of books are often indicated by the item's call number or a local subject heading (MARC 690). Some items may be included in both online lists and physical collections.

Twenty-one items are identified as locally-authored through inclusion in local lists or collections.

Table 2

Number of Locally-Authored Items in Lists and Collections

\begin{tabular}{lc}
\hline List or Collection Type & Items \\
\hline Online Lists & 2 \\
\hline Physical Collections & 18 \\
${ }^{*}$ Local History Collections are included & 1 \\
\hline Online Lists + Physical Collections & 21
\end{tabular}

Note. These lists and collections may be based on the city, region, or province of the author or genre. 
Table 3

Types of Local Lists and Collections

List/Collection Type Definition and example Items

City, Region, and E.g. BC and Canadian Fiction, Books by a Local

Province Author or Publisher, Books by [Region] Authors.

City only

E.g. [Location] Collection

$9^{a}$

\begin{tabular}{lll}
\hline Local History & E.g. "Local History Collection" & 10
\end{tabular}

Total

a7 of the 9 items in city collections/lists are from BC3, which uses MARC 690 (Local Subject Headings) and call numbers/shelving locations to identify the items as part of [Location] Collection.

\section{Notes}

Six items were identified as locally-authored through Notes in the MARC record (e.g. 500, 590). Three items used the phrase "local author," and three items identified the location of the author, i.e. "[Location] author".

\section{Discussion}

Collection policies and item metadata were selected for analysis with the hypothesis that the two would inform each other, as item selection and cataloguing were discussed throughout the literature. It was expected, for example, that if policies promoted the inclusion of items by local authors, there may be consistent methods for identifying these authors or use of local collections. However, neither the policies nor the metadata demonstrated cohesive methods toward inclusion or consistent identification of locally-authored items. Instead, the policies present both opportunities and barriers for the inclusion of these items in library collections, and the various methods used in the metadata can provide insight into possibilities of how locallyauthored items could be identified.

\section{Opportunities to Include Local Authors}

From the analysis of collection policies, it is evident that the libraries included in this study value meeting the information needs of their communities. These needs are 
recognized as diverse and varied and relate to all aspects of social and personal life. The emphasis on community-oriented collections throughout the collection policies provides opportunities to include locally-authored items, as these items represent the perspectives and experiences of community members, and are likely relevant to interests of the community. Additionally, the focus on collection diversity within the policies opens the possibility of acquiring locally-authored items, particularly those that are self-published, as these are represent diverse points of view that may differ from items conventionally published. Locally-authored items present a unique local voice that may meet the diverse interests of local community members.

Though these themes indicate support of locally-authored items, only half (six) of the libraries directly reference items of local interest or significance within their policies. The broad description of local significance including local creators or local history, and provincial or even Canadian content, supports the inclusion of items by local authors about various subjects and from the community or nearby. However, language such as "local significance" is not clearly defined in the policies, and different interpretations may result in exclusion of local authors who choose to self-publish, have not sold their works widely, or who may not have lived in the community for a long period. While the reference to local interest in these policies supports the inclusion of locally-authored items, the lack of clear definitions may complicate the extent of these opportunities.

\section{Barriers for Including Local Authors}

The remaining themes that focus on the quality (eight policies) and value (seven policies) of items may create barriers to the inclusion of locally-authored items. While quality sometimes refers to the physical upkeep of an item, policies focus on the quality of contents in terms of subject or writing. As discussed in the literature, this can present a challenge for local authors who choose to self-publish as they do not have the same team of editors, reviewers, marketers, and publishers that ensure a certain level of quality of content and format of published items. This results in general expectations of lower quality of self-published items and a reluctance to include these in collections (Dilevko \& Dali, 2006; Mullock, 2019; DeWild \& Jarema, 2015), as reflected in the studied policies. Similarly, without the support of traditional publishing companies, it may be difficult for authors to establish the importance of their work, though these items, 
however published, may be valuable currently and in the future as representations of the community's values, perspectives, and history.

Similarly, the themes of reviews (nine policies) and reputation of creator (six policies) can create barriers for local authors who are new or choose to self-publish. New authors may not already have a reputation in the literary world, and self-published items are rarely reviewed in traditional review journals and are excluded from vendor lists (Dilevko \& Dali, 2006; Culley, 2017; DeWild \& Jarema, 2015). Without unpaid reviews or marketing teams to establish public recognition and reputation, selfpublished and new local authors may be overlooked for acquisition. Some policies do, however, acknowledge the professional opinion of librarians when selecting items, though this may place additional burden on library staff to research the item. These criteria can make it difficult for locally-authored items to be included in library collections.

\section{Metadata Discussion}

The analysis of metadata demonstrates that there is no consistent method for identifying local authorship. While 38 of 78 items from the sample indicate they are "local," the methods and specificity vary. Some items are identified by the location of the author or genre, and some specify the city and region, while others indicate only the province. This variation occurs not only between different libraries, but even within libraries. This can negatively affect findability and accessibility of these items, as it makes it difficult for library users to know how to search for locally-authored items and identify them as such.

\section{Challenges for Identifying "Local”}

While identifying locally-authored items can support accessibility of items for the user and support local authors, there are challenges that may affect how or why libraries choose to identify "local" metadata. Information about authors is not static. For example, one item from AB4 states in MARC Notes: "This is the first novel by this author who was raised in [AB4] and now lives in Edmonton." It is unrealistic to expect libraries to maintain this kind of metadata about authors. Similarly, when libraries are part of consortiums that share an online catalogue, metadata that uses the phrase "local author" loses meaning when that item's record is accessed by library users in numerous 
communities. When considering these challenges, it is not surprising that libraries vary in how locally-authored items are identified.

\section{Recommendations and Future Research}

The barriers created through collection policies, and the various methods of identifying locally-authored items in the metadata demonstrate that there are areas for future work and research. As Pacer (2013) and Mullock (2019) recommend, selection criteria should be broadened to better include self-published and local voices. For example, instead of relying on professional reviews, libraries can utilize the social media tools patrons use to discuss and rank authors and topics (Pacer, 2013), or establish a volunteer review board (Mullock, 2019). Adapting these policies will provide opportunities for self-published, local authors to be included in collections while still meeting the intent of the selection criteria. Additionally, libraries can modify their collection policies to state preference for items of local interest or by local authors and privilege these voices through exemptions to the criteria. In this way, policies can remain largely unchanged, while creating opportunities to support these authors.

The use of metadata to support findability of locally-authored items is an area for further research. As this study demonstrates, there is a need for guidelines or best practices when using either MARC records or online cataloguing metadata to better identify local authorship. For example, to address the changing "local" status of authors, $B C 1$ and $A B 2$ utilize various online lists of authors from the province, region, or city that can be included with the item on the catalogue. Changes to online lists do not require changes to bibliographic records and can be easily understood and used by library users from various communities within the consortium. Physical collections and call numbers can also be utilized. For example, while SK3 and BC2 share items in a consortium, the local call numbers identify that the items are located in SK3's Local History Collection or BC2's "Location" Collection. These suggestions can provide starting points for additional research into how to best support the inclusion and access of locally-authored items.

This study was limited to twelve urban public libraries in three Canadian provinces. Expanding the sample to include additional libraries and items, or to include rural public libraries, and libraries from other provinces will provide additional insight into 
how libraries include and identify locally-authored items. It is also important to note that some public libraries support local authors through other services such as library displays, writing and publishing workshops, book signings, and author talks, all of which provide support for local authors in meaningful ways. Broadening the scope of this research to include an analysis of these programs and services could continue to provide insight into how libraries support local authors.

\section{Conclusion}

The use of qualitative and systematic analysis of collection policies and locallyauthored item metadata demonstrates that while there are instances in which libraries work to include locally-authored items and support their accessibility, there is no consistent way in which this is achieved. Libraries develop their collections to meet the various needs of diverse communities, but only half of the libraries included in this study acknowledge the importance of items of local interest in their collection policies. The emphasis within collection policies on the quality of items and the reputation of the creators can create barriers to including these items that may represent the values, perspectives, and shared history of the community. Additionally, less than half of the items analyzed are identified as locally-authored, and this is identified using various methods and with varying levels of specificity. Overall, this research demonstrates that libraries provide support to local authors through including their works in library collections and making items findable to patrons in various and inconsistent ways. Perhaps this is because there are challenges to naming "local" authors, especially when catalogue records are shared within consortia. Modifying collection policies to define "local" and privilege these voices, as well as continued research into best practices for cataloguing self-published and locally-authored items will provide libraries with a framework for better supporting local authors to continue to provide materials that resonate with the local community.

\section{Conflict of Interest Statement}

The author declares that there is no conflict of interest. 


\section{References}

American Library Association. (2006, July 26). Diverse collections: An interpretation of the Library Bill of Rights. ALA.

http://www.ala.org/advocacy/intfreedom/librarybill/interpretations/diversecollectio $\underline{\text { ns }}$

American Library Association. (2009, July 23). Education and information literacy: An interpretation of the Library Bill of Rights. ALA. http://www.ala.org/advocacy/intfreedom/librarybill/interpretations/education

Bijali, A., \& Khan, S. C. (2018). Marketing of local history collection of public libraries in the age of IT. International Journal of Information Dissemination and Technology, 8(2), 96-98. https://doi.org/10.5958/2249-5576.2018.00020.1

Bowen, G. A. (2009). Document analysis as a qualitative research method. Qualitative Research Journal, 9(2), 27-40. https://doi.org/10.3316/QRJ0902027

Bradley, J., Fulton, B., \& Helm, M. (2012). Self-published books: An empirical "snapshot". Library Quarterly, 82(2), 107-140. https://doi.org/10.1086/664576

Culley, J. (2017). Self-published books: Should libraries buy or not? The Southeastern Librarian, 65(1), 1-6. https://digitalcommons.kennesaw.edu/seln/vol65/iss1/2

Dawson, L. (2008). The role of self-publishing in libraries. Library Trends, 57(1), 43-51. https://doi.org/10.1353/lib.0.0021

DeWild, M., \& Jarema, M. (2015). Supporting self-publishing and local authors: From challenge to opportunity. In R. P. Holley (Ed.), Self-publishing and collection development: Opportunities and challenges for libraries (pp. 21-26). Purdue University Press.

Dilevko, J., \& Dali, K. (2006). The self-publishing phenomenon and libraries. Library \& Information Science Research, 28(2), 208-234. http://doi.org/10.1016/j.lisr.2006.03.003

England, G. A. (1948). Local author collections in libraries. College and Outreach Libraries, 9, 339-342. https://doi.org/10.5860/crl 0904339

Gross, J. M. S. (2018). Document analysis. In B. B. Frey (Ed.), The SAGE encyclopedia of educational research, measurement, and evaluation (pp. 545-548). SAGE Publications, Inc. https://dx.doi.org/10.4135/9781506326139 
Holley, R. (2015). Self-publishing and bibliographic control. In R. P. Holley (Ed.), Selfpublishing and collection development: Opportunities and challenges for libraries (pp. 21-26). Purdue University Press.

Kelly, M. (2015). Collection development policies in public libraries in Australia: A qualitative content analysis. Public Library Quarterly, 34(1), 44-62. https://doi.org/10.1080/01616846.2015.1000783

Mullock, H. (2019). Self-published memoirs in libraries: Challenges, opportunities, and recommendations. iJournal, 4(2), 39-50. https://theijournal.ca/index.php/ijournal/article/view/32547

Pacer, M. (2013). Small press and self-published books: A collection development dilemma. Against the Grain, 25(3), 33-34. https://doi.org/10.7771/2380176X.6521

Saldaña, J. (2009). The coding manual for qualitative researchers. Sage Publications Ltd.

Sandy, H. M. (2016). The role of public libraries in self-publishing: Investigating author and librarian perspectives. Journal of Library Administration, 56(8), 893-912. https://doi.org/10.1080/01930826.2015.1130541

Statistics Canada. (2019, February 20). Population and dwelling count highlight tables, 2016 census. StatsCan. https://www12.statcan.gc.ca/censusrecensement/2016/dp-pd/hlt-fst/pdpl/Table.cfm? Lang=Eng\&T=302\&SR=1\&S=86\&O=A\&RPP=9999

Tuncer, N., \& David, R. (2019). The cataloging of self-published items. Cataloging \& Classification Quarterly, 57(4), 206-226. https://doi.org/10.1080/01639374.2019.1602091

White, M. D., \& Marsh, E. E. (2006). Content analysis: A flexible methodology. Library Trends, 55(1), 22-45. https://doi.org/10.1353/lib.2006.0053 